\title{
Measurement and prediction of tomato canopy apparent photosynthetic rate
}

\author{
Jian Yin ${ }^{1}$, Xinying Liu ${ }^{1}$, Yanlong Miao ${ }^{1}$, Yang Gao ${ }^{2}$, Ruicheng Qiu ${ }^{1}$, Man Zhang ${ }^{1 *}$, \\ Han $\mathrm{Li}^{2}$, Minzan $\mathrm{Li}^{1}$ \\ (1. Key Laboratory of Modern Precision Agriculture System Integration Research, Ministry of Education, China Agricultural University, \\ Beijing 100083, China; 2. Key Laboratory of Agricultural Information Acquisition Technology, Ministry of Agriculture and Rural Affairs, \\ China Agricultural University, Beijing 100083, China)
}

\begin{abstract}
Given the lack of technical conditions and research methods, instruments that can measure the canopy apparent photosynthetic rate have low precision and are rarely studied. Comparative studies on canopy apparent photosynthetic rate and single leaf photosynthetic rate are also relatively few. This study aims to measure and predict the canopy apparent photosynthetic rate of tomato. A canopy apparent photosynthetic rate measuring system, which was comprised of a wireless sensor network (WSN), an assimilation chamber, and a LI-6400XT photosynthetic rate instrument was established. The system was used to determine the greenhouse environmental parameters and $\mathrm{CO}_{2}$ absorptive capacity of the whole growth stage of tomato. A semi-closed assimilation chamber was designed as a side opening to conveniently measure the canopy apparent photosynthetic rate. WSN nodes were placed in the chamber to monitor environmental parameters, including air temperature, air humidity, and assimilation chamber temperature. A grid and pixel conversion method was used to measure the whole plant leaf areas of tomato. As a semi-closed measurement system, the assimilation chamber was used to calculate the canopy apparent photosynthetic rate. To conduct a comparative research on the canopy apparent photosynthetic rate and the single leaf photosynthetic rate, the LI-6400XT portable photosynthesis system was used to measure the single leaf photosynthetic rate, and the support vector machine was used to establish the prediction model of canopy apparent photosynthetic rate. The experimental results indicated that the correlation coefficients of the photosynthesis prediction model in the seeding and flowering stages were 0.9420 and 0.9226 , respectively, showing the high accuracy of the SVM model.
\end{abstract}

Keywords: photosynthetic rate, tomato, assimilation chamber, SVM, photosynthesis prediction model DOI: $10.25165 /$ j.ijabe.20191205.4982

Citation: Yin J, Liu X Y, Miao Y L, Gao Y, Qiu R C, Zhang M, et al. Measurement and prediction of tomato canopy apparent photosynthetic rate. Int J Agric \& Biol Eng, 2019; 12(5): 156-161.

\section{Introduction}

The canopy apparent photosynthetic rate has greater importance than the net photosynthetic and ecological system photosynthetic rates ${ }^{[1,2]}$ in agro-forestry ecological research. The measurement of canopy apparent photosynthetic rate is relatively complicated, and its accuracy is low. Therefore, designing a fast and high accurate canopy apparent photosynthesis measurement device has been the focus of many studies.

Since the 1930s, the measurement of canopy apparent photosynthetic rate has received considerable attention worldwide. $\mathrm{Niu}^{[3]}$ designed a rapid and convenient assimilation chamber to

\section{Received date: 2019-02-17 Accepted date: 2019-07-22}

Biographies: Jian Yin, Master, research interest: agricultural informatization, Email: 465170245@qq.com; Xinying Liu, PhD candidate, Associate Professor, research interest: agricultural informatization, Email: 376846834@qq.com; Yanlong Miao, Master candidate, research interest: agricultural informatization, Email: hua20102013@163.com; Yang Gao, Master candidate, research interest: agricultural informatization, Email: 163hfuthilda@qq.com; Ruicheng Qiu, PhD candidate, research interests: plant phenotyping, Email: 0908140704@, cau.edu.cn; Han Li, PhD, Associate Professor, research interests: precision agriculture; Minzan Li, PhD, Professor, research interest: precision agriculture, Email: limz@cau.edu.cn

*Corresponding author: Man Zhang, $\mathrm{PhD}$, Professor, research interest: precision agriculture. China Agricultural University, P.O. Box 125, Qinghua East Road, Haidian District, Beijing 100083, China. Tel: +86-10-62737188, Email: cauzm@cau.edu.cn. measure canopy apparent photosynthetic rate in the field. Wu et al. ${ }^{[4]}$ used the CI-310 portable photosynthesis measurement system to measure the canopy apparent photosynthetic rate and established photosynthetic rate prediction models on the basis of the support vector machine (SVM). SVM was used to find the best tradeoff between the complexity and the learning ability of the model on the basis of limited sample information. It can solve the problems of small sample, nonlinear, high dimension, and local minima. To improve the prediction accuracy of the model, particle swarm optimization (PSO), genetic algorithm, and grid search were used to optimize the parameters of SVM. The predicting accuracy was $82 \%$. Long et al. ${ }^{[5]}$ designed a small assimilation chamber to measure cucumber canopy apparent photosynthetic rate, and the measurement accuracy of the assimilation chamber was less than $\pm 0.8 \mathrm{mg} / \mathrm{dm}^{2} \cdot \mathrm{h}$ in natural and simulated light. Kong et al. ${ }^{[6]}$ studied the canopy apparent photosynthetic rate of rice varieties (lines) with different genotypes at grain filling stage. Although the aforementioned studies investigated the canopy apparent photosynthetic rate, the infrared gas analyzer was generally used to measure the canopy apparent photosynthetic rate. However, the measurement accuracy of the system is low, and the data need to be recorded manually.

Tomato is one of the main greenhouse crops in the world because of its wide cultivation and rich nutrition ${ }^{[7,8]}$. Tomato was selected as the research object in this study. The environmental parameters in greenhouse, including time, air temperature, air 
humidity, and light intensity, were automatically measured by the wireless sensor network (WSN) $)^{[9,10]}$. To compare the canopy apparent photosynthetic rate with the net photosynthetic rate, the WSN, assimilation chamber, and LI-6400XT photosynthetic rate instrument were used to measure canopy apparent photosynthetic rate.

\section{Materials and methods}

\subsection{Experimental design}

The experiment was performed from July 6 to August 20, 2018, and the experiment was conducted in an experimental greenhouse located at the north side of the College of Information and Electrical Engineering, China Agricultural University. The irrigation of culture substrate and nutrient solutions was unified to maintain suitable conditions for tomato growth. When 4-6 true leaves appeared in the tomato, 60 seedlings were selected and planted in a flowerpot with a diameter of $20 \mathrm{~cm}$ and a depth of $35 \mathrm{~cm}$. The vermiculite to perlite ratio was $3: 2$.

This research is divided into four sections, namely, experimental design, data collection, data analysis, and model development. For developing the canopy apparent photosynthetic rate prediction models based on SVM, the measuring system was designed and used to monitor the diurnal dynamics of photosynthetic rate.

\subsubsection{Measurement of net photosynthetic rate}

The LI-6400XT portable photosynthesis system is an important measurement tool in the field of ecology. It can measure multiple physiological indices, such as photosynthetic, respiration, transpiration, and fluorescence rates. To measure the light and $\mathrm{CO}_{2}$ corresponding curve, the LED chamber and $\mathrm{CO}_{2}$ injection system were used to control the light intensity and $\mathrm{CO}_{2}$ concentration in the analyzers ${ }^{[11]}$, as shown in Figure 1.

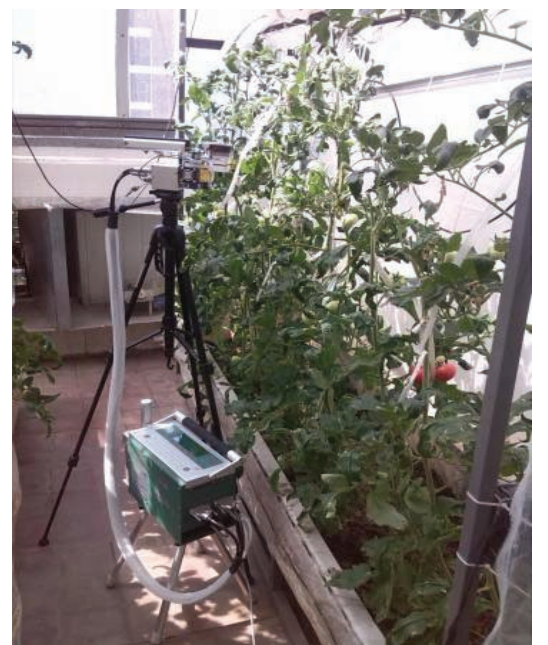

Figure 1 LI-6400XT photosynthetic rate instrument

\subsubsection{Measurement of canopy apparent photosynthetic rate}

Figure 2 shows the working principle of the system. The assimilation chamber, sensor node, and portable photosynthesis system were used to measure the plant $\mathrm{CO}_{2}$ assimilation. The $\mathrm{CO}_{2}$ gas resources, control instrument, solenoid valve, $\mathrm{CO}_{2}$ sensor, and mixing fan were used to control the $\mathrm{CO}_{2}$ concentration in the assimilation chamber.

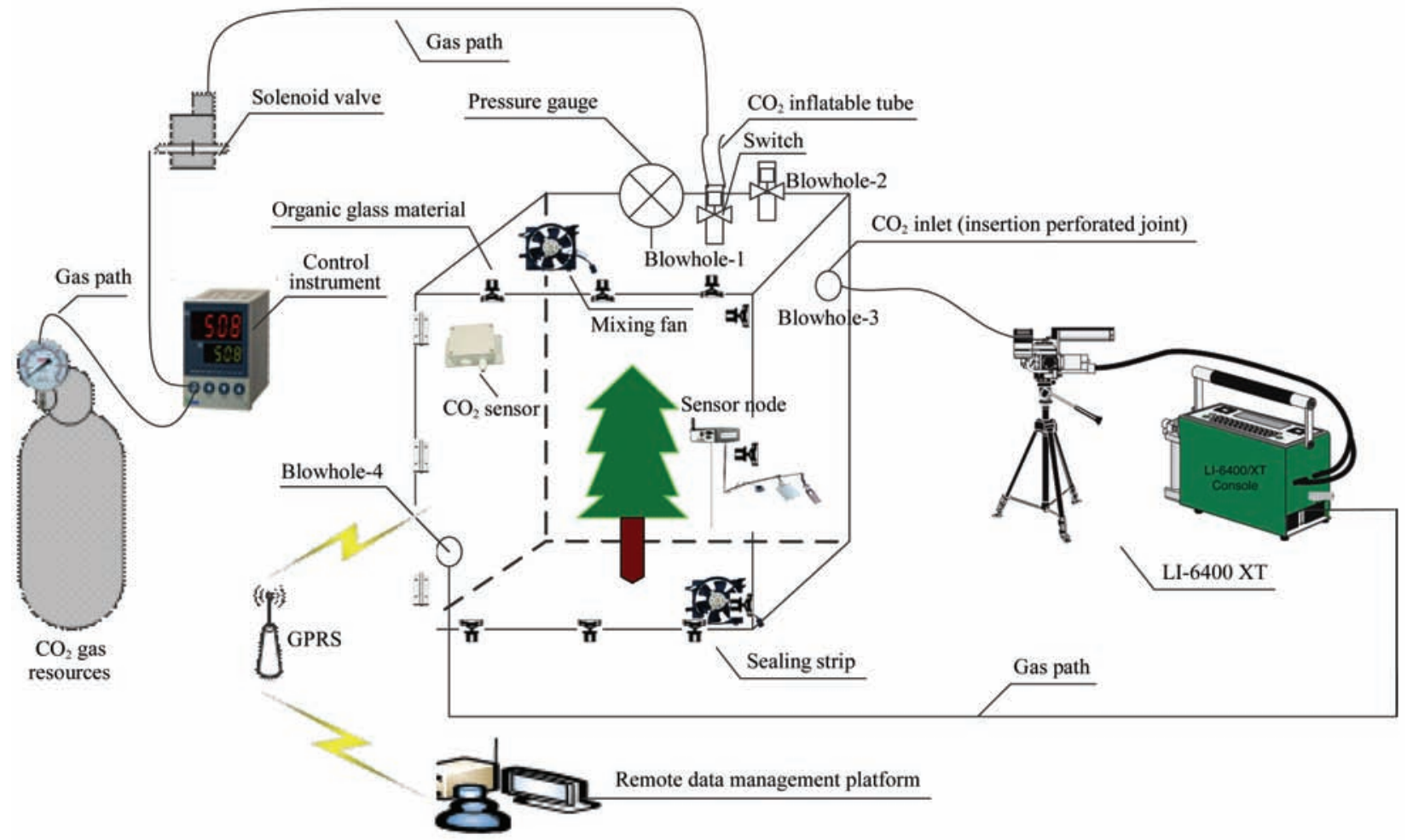

Figure 2 Structure of the system

(1) Design of the semi-closed assimilation chamber

The assimilation chamber was $0.7 \mathrm{~m} \times 0.7 \mathrm{~m} \times 1.2 \mathrm{~m}$ and was made up of transparent plexiglass. The side door could be completely opened to conveniently place the sample into the assimilation chamber. The side door was made up of a shaft, a chain, and a double-sealing strip to ensure air tightness.

The box has four small holes, and a perforation joint was used to connect the air tube. Blowhole-1 was used to transport $\mathrm{CO}_{2}$ into the box, and Blowhole-2 was used to decrease the pressure. Blowhole-3 was used to place the LI-6400XT gas analyzer into the assimilation chamber. The gas in the box was transported to the LI-6400XT analyzer through Blowhole-4. The mixing fans in the assimilation chamber were used to mix the internal gas rapidly. The $\mathrm{CO}_{2}$ gas resources, control instrument, solenoid valve, $\mathrm{CO}_{2}$ 
sensor, and mixing fans were used to control the $\mathrm{CO}_{2}$ concentration in the closed assimilation chamber.

The environmental parameters in the assimilation chamber, including time, air temperature, air humidity, and light intensity, were determined using a WSN system, and the acquisition interval was set to $3 \mathrm{~min}$.

(2) Control and measurement system of $\mathrm{CO}_{2}$

Figure 3 shows the diagram of the $\mathrm{CO}_{2}$ control and measurement system, which is comprised of an assimilation chamber, a desiccant, a filter, an air pump, a control instrument, a $\mathrm{CO}_{2}$ sensor, and a $\mathrm{CO}_{2}$ analysis probe. The flow rate of the system was controlled by an air pump. The gas was dried and purified by chemicals and was subsequently introduced into the analysis probe. The $\mathrm{CO}_{2}$ concentration was measured by analysis probe and then transferred to the assimilation chamber.

In the assimilation chamber, the plant absorbs $\mathrm{CO}_{2}$ because of photosynthesis. The semi-closed measurement system was made up of $\mathrm{CO}_{2}$ gas resources, a control instrument, and a solenoid valve to keep $\mathrm{CO}_{2}$ concentration constant. The assimilation chamber was connected to the control instrument via the $\mathrm{CO}_{2}$ sensor. Figure 3 shows the diagram of the $\mathrm{CO}_{2}$ measurement system. A transparent $\mathrm{CO}_{2}$-insulated plastic pipe was selected to deliver the gas. The diameter of the pipe is $10 \mathrm{~mm}$.

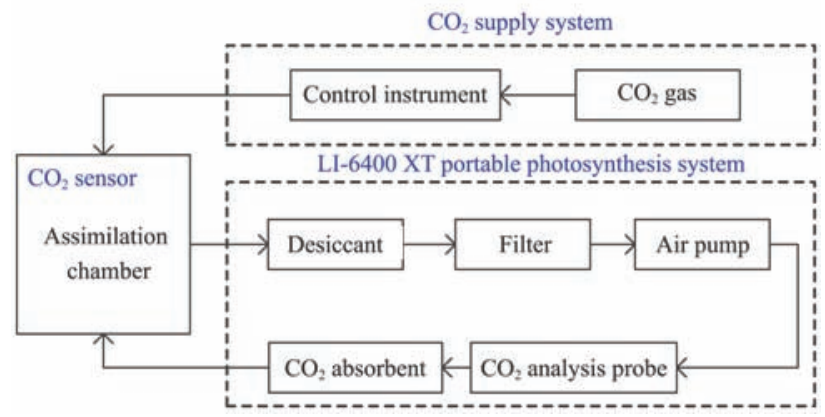

Figure 3 Working principle of the system

\subsection{Measurement methods}

\subsubsection{Zero calibration of LI-6400XT}

LI-6400XT must be calibrated to ensure the accuracy of the measured data. The $\mathrm{CO}_{2}$ and water of the whole closed system were completely absorbed by the LI-6400XT. The zero point of the instrument is normal if the $\mathrm{CO}_{2}$ and moisture sensor readings are within $\pm 5 \mu \mathrm{mol} / \mathrm{mol}$ and $\pm 0.5 \mathrm{mmol} / \mathrm{mol}$, respectively. When the readings are beyond this range, zero point calibration is required, or the chemicals of LI-6400XT need to be replaced.

\subsubsection{Measurement of net photosynthetic rate}

(1) Induction of photosynthetic rate

Plants will take some time to acclimate and reach the maximum photosynthetic rate. Therefore, photosynthetic induction is needed ${ }^{[12,13]}$. In natural conditions, the saturation intensity of C 3 plants is approximately $1000 \mu \mathrm{mol} / \mathrm{m}^{2} \cdot \mathrm{s}^{[14,15]}$. The measurements were obtained until the photosynthetic rate fluctuation was less than $0.2 \mu \mathrm{mol} / \mathrm{mol}$ for stabilization. Moreover, the stomatal conductance (Cond), intercellular $\mathrm{CO}_{2}$ concentration $(\mathrm{Ci})$, and transpiration rate $(\mathrm{Tr})$ were all greater than 0 .

\section{(2) Matching operation of the LI-6400XT}

The matching operation was needed for LI-6400XT when the $\mathrm{CO}_{2}$ concentration was changed to reduce internal system errors and obtain accurate measurements ${ }^{[16,17]}$. When matching, the same gas sample flowed through the sample and reference chambers. Moreover, a new balance between two $\mathrm{CO}_{2}$ infrared gas analyzers (IRGAs) was reached in the photosynthesis system. Large fluctuation in the readings also required the matching operation. To obtain reliable data, the value of the net photosynthetic rate was recorded when the fluctuation of $\mathrm{CO}_{2}$ concentration was less than $0.2 \mu \mathrm{mol} / \mathrm{mol}$. The value of a single leaf net photosynthetic rate was stable, and the values of Cond, $\mathrm{Ci}$, and $\operatorname{Tr}$ were greater than 0 .

(3) Measurement of response curve

The middle part of fully expanded functional leaves, located at the second or third leaf from the top to the bottom was measured. To expand the data range, the two-factor interaction experiment was conducted by artificially controlling $\mathrm{CO}_{2}$ concentration and light intensity. The 6400-01 $\mathrm{CO}_{2}$-injector system (LI-6400XT portable photosynthesis system accessory) was used to control $\mathrm{CO}_{2}$ concentration, and its value was set to $400,600,800,1000,1300$, 1500 , and $1700 \mu \mathrm{mol} / \mathrm{mol}$. The $6400-02 \mathrm{~B} \mathrm{red} / \mathrm{blue}$ LED light source (light source located on the leaf chamber of LI-6400XT portable photosynthesis system) was used to adjust light intensity, and its value was set to $1200,900,600$, and $300 \mu \mathrm{mol} / \mathrm{m}^{2} \cdot \mathrm{s}$.

The experiments were carried out in five growth stages, and the data in the two growth stages, namely, late seeding and full flowering stages, were analyzed in this study ${ }^{[6,17]}$. A similar method for measuring the photosynthetic rate was used at each growth stage. A total of 60 selected tomato samples were measured, and 182 sets of experimental data, including air temperature, humidity, soil temperature, soil humidity, $\mathrm{CO}_{2}$ concentration, and light intensity, were obtained.

2.2.3 Measurement of canopy apparent photosynthetic rate

(1) Air tightness testing

The air tightness of the assimilation chamber directly affects the reliability and accuracy of the results. The gas leakage rate not only depends on chamber tightness but also relates to wind and system flow rate. The experiments were conducted in a relatively closed greenhouse, where the wind could be neglected and the influence of flow speed and air tightness of the box were considered.

The $\mathrm{CO}_{2}$ concentration in the assimilation chamber was less than the atmospheric $\mathrm{CO}_{2}$ concentration to observe gas variation conveniently. The maximum experimental concentration was $2190 \mu \mathrm{mol} / \mathrm{mol}$, and the flow rate was set to $680 \mu \mathrm{mol} / \mathrm{s}$, which was the maximum flow rate of LI-6400XT. The acquisition interval was set to $10 \mathrm{~s}$.

(2) Measurement of the plant $\mathrm{CO}_{2}$ assimilation

The experimental tomato was placed in the assimilation box. The black foam pad was placed under the box and then sealed using a sealing strip. The flow rate of the LI-6400XT gas pump was set to $500 \mathrm{mmol} / \mathrm{s}$. The pipe switch above the assimilation chamber was opened when the flow rate was stable. The $\mathrm{CO}_{2}$ gas resources, control instrument, solenoid valve, $\mathrm{CO}_{2}$ sensor, and mixing fan were used to control the $\mathrm{CO}_{2}$ concentration in the assimilation chamber. The $\mathrm{CO}_{2}$ in the leaf chamber of LI-6400XT was pumped up from the assimilation chamber and then precisely measured. Temperature and humidity rapidly increased because of the high sealing, high light transmission of the box, and transpiration of the tomato in the box. Therefore, the measurement process was maintained within $15 \mathrm{~min}$, and the data acquisition interval was set to $15 \mathrm{~s}$. The observation value was recorded. Furthermore, the air temperature and humidity in the assimilated chamber was measured by the sensor nodes.

(3) Measurement of the whole tomato leaf area

In this study, the grid and pixel conversion method was used to 
measure the whole plant leaf areas of tomato. The grid square areas were labeled on a coordinate paper. First, the paper was closely fixed on a hard and non-deforming plastic plate. Second, the leaf on the plastic plate was flattened using a transparent plastic plate and was photographed (Figure 2). The red square and leaf pixel were identified by MATLAB and were processed to calculate calculated by using Equation (1):

$$
S=\frac{N_{A}}{N_{B}} S_{C}
$$

where, $N_{A}$ and $N_{B}$ are the number of leaf pixels and selected square pixels, respectively. $S_{C}$ is the square area. The area of each leaf was accumulated to determine the leaf area of the whole plant.

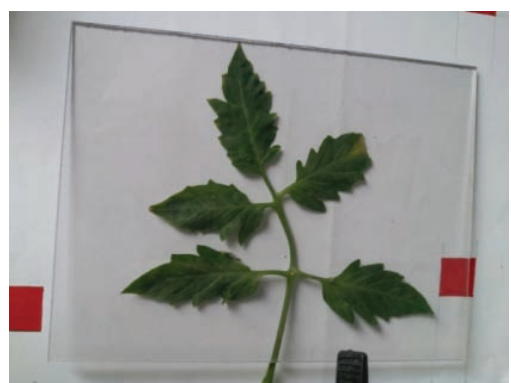

Figure 4 Measurement of tomato leaf areas

(4) Calculation of canopy apparent photosynthetic rate

Equation (2) shows the formula of plant photosynthetic rate:

$$
P_{n}=\frac{10^{2}}{S}\left(V \times 10^{3} \times 60\right) \frac{\Delta c}{\Delta t}\left(\frac{44}{22.4} \times \frac{P}{101.3} \times \frac{273}{273+T} \times 10^{-6}\right)
$$

where, $S, V$, and $\Delta t$ are the leaf area of the whole plant in the assimilation chamber $\left(\mathrm{dm}^{2}\right)$, the gas volume in the assimilation chamber $\left(\mathrm{dm}^{3}\right)$, and the interval between the first and last photosynthetic rate of the plant canopy, $\mathrm{mg} / \mathrm{dm}^{2} \cdot \mathrm{h} ; P$ is the pressure of the atmosphere, $\mathrm{Pa}$; and $T$ is the temperature inside the chamber, ${ }^{\circ} \mathrm{C}^{[19]}$.

\subsection{Data analysis methods}

First, the error or negative data need to be removed. The influence of environmental factors, operator factors, or experimental instrument factors inevitably cause errors in the experimental data, such as inadequate induction, large variation of light intensity, or unstable airflow, which may lead to an unreliable photosynthetic rate ${ }^{[20]}$. Thus, the experimental data measured by the WSN system and LI-6400XT must be matched in space and the leaf areas via comparative reference ${ }^{[18]}$. The leaf areas were measuring time after the gas is stable (s), respectively; $P_{n}$ is the

time to ensure the quality of the model.

\subsubsection{Data preprocessing}

Generally, the sampled data should be normalized according to Equation (3) to eliminate the influence of dimension and improve SVM convergence performance. After processing, the data of minimum and maximum values were normalized to $[-1,1]$.

$$
x_{k}^{\prime}=2 \times \frac{\left(x_{k}-x_{\min }\right)}{\left(x_{\max }-x_{\min }\right)}-1
$$

where, $x_{\max }$ and $x_{\min }$ represent the maximum and minimum values of each variable, respectively.

\subsubsection{SVM prediction model}

The advantageous precondition to build models is to select the appropriate regression parameters. For SVM, the kernel function (radial basis function) parameter $\mathrm{g}$ and the penalty factor $\mathrm{c}$ have definitive action in the learning accuracy and generalization ability of regression model.

The evaluation indices of performance include root-meansquare error (RMSE), average relative error (ARE), mean absolute error (MAE), and correlation coefficient (R).

\subsubsection{PSO}

PSO was used to optimize the parameter $g$ and the penalty factor $\mathrm{c}$ to improve prediction stability and utilize the limited data fully. In the PSO algorithm, the solution of each optimization problem is considered a particle and is then extended to $\mathrm{N}$-dimensional space. The position of particle $\mathrm{I}$ in the $\mathrm{N}$-dimensional space was expressed as a vector. All particles have an adaptive value. The best parameter was taken by the fitness function, which was used to adjust the velocity and position of the particles ${ }^{[21,22]}$

\section{Results and analysis}

\subsection{Analysis of air tightness}

The air tightness curves are shown in Figure 5. As shown in the figure, the atmospheric pressure, air temperature, and relative humidity were maintained (i.e., $105.5 \mathrm{kPa}, 36.38^{\circ} \mathrm{C}-38.58^{\circ} \mathrm{C}$, and 60.39\%-65.69\%). The input $\mathrm{CO}_{2}$ concentration was $2190 \mu \mathrm{mol} / \mathrm{mol}$, and the concentration variation of $\mathrm{CO}_{2}$ was less than $1 \mu \mathrm{mol} / \mathrm{mol}$. In Figure 5, the concentration variation of $\mathrm{CO}_{2}$ was less than $1 \mu \mathrm{mol} / \mathrm{mol}$ when the assimilation chamber was placed outside the greenhouse. The pressure, air temperature, and relative humidity in the greenhouse were maintained at $101.3 \mathrm{kPa}, 34.69^{\circ} \mathrm{C}-36.79^{\circ} \mathrm{C}$, and $55.56 \%-60.69 \%$. The result indicates that the assimilation chamber was tightly sealed.

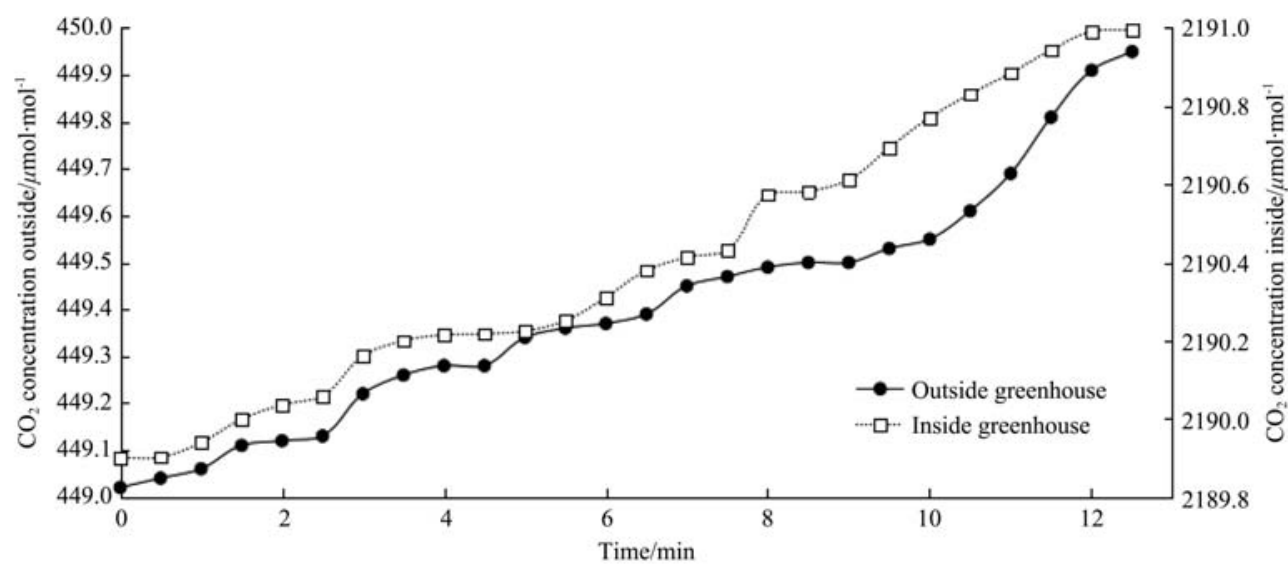

Figure 5 Air tightness curve

Figure 6 shows the diurnal dynamics of the photosynthetic rate 3.2 Difference of diurnal dynamics (1) Seeding stage The diurnal dynamics of canopy apparent photosynthetic rate 
shows a single-peak curve. The canopy apparent photosynthetic rate significantly increased from 8:30 to 13:00, and the ratio was $1: 18.41$. As time went by, the canopy apparent photosynthetic rate decreased with the decrease of light intensity. The measured value was $14.66 \mathrm{mg} / \mathrm{dm}^{2} \cdot \mathrm{h}$ at 18:00 and was approximately half of the maximum.

The net photosynthetic rate significantly increased from 8:30 to $13: 30$, and the ratio was $1: 5.81$. With the increase of light intensity, the increase of canopy apparent photosynthetic rate was more obvious than that of the net photosynthetic rate. In the graph, the diurnal dynamics of net photosynthetic rate also shows a single-peak curve.

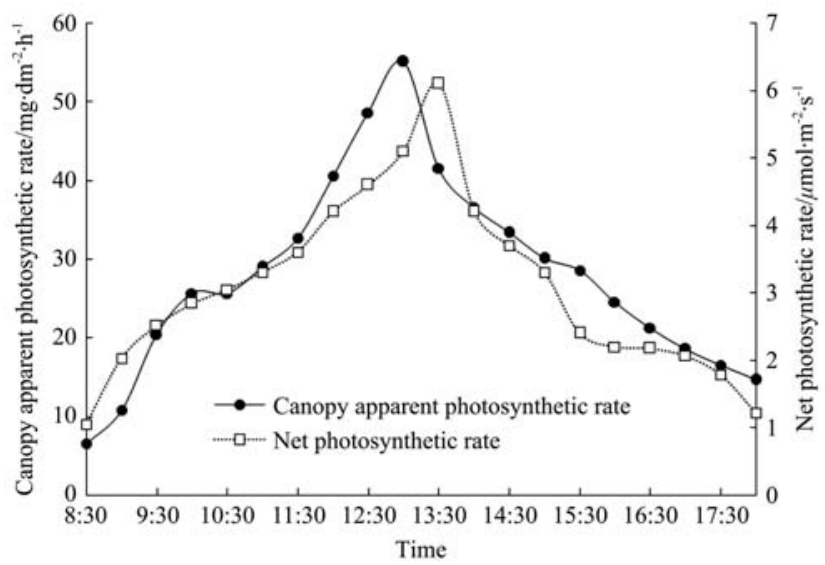

Figure 6 Diurnal dynamics at the seeding stage

(2) Flowering stage

Figure 7 shows the diurnal dynamics of two situations at the flowering stage. The diurnal dynamics of the canopy apparent photosynthetic rate presented a double-peak curve. The canopy apparent photosynthetic rate significantly increased from 8:30 to 13:00, and the ratio was 1:2.74 and presented midday depression. The midday depression of the canopy apparent photosynthetic rate slowly disappeared with the decrease of temperature and then increased to the second peak. As time went by, the canopy apparent photosynthetic rate decreased with the decrease of light intensity. The measured value was $19.56 \mathrm{mg} / \mathrm{dm}^{2} \cdot \mathrm{h}$ at $18: 00$, and the value was approximately 1.2 times of the maximum peak.

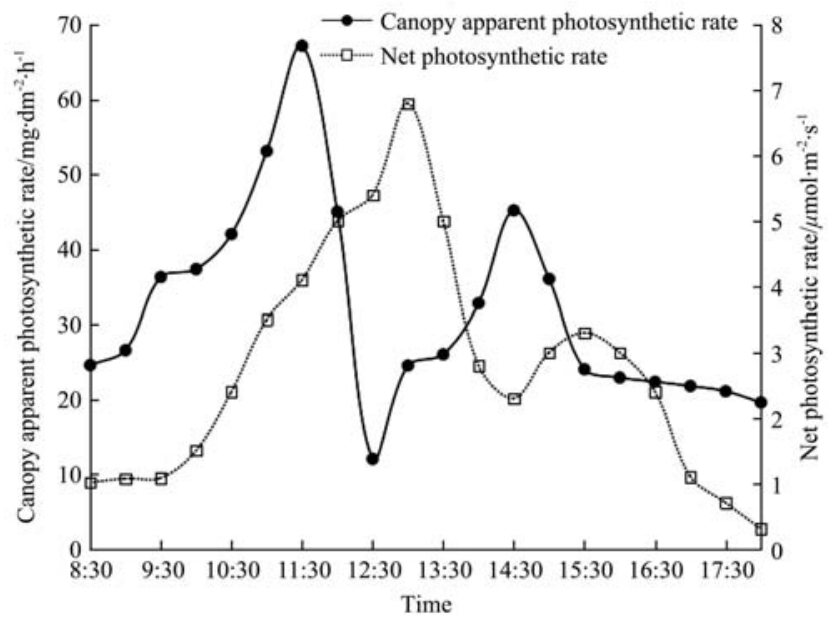

Figure 7 Diurnal dynamics at the flowering stage

The net photosynthetic rate significantly increased from 8:30 to $13: 30$, and the ratio was 1:6.74. Within the increase of light intensity, the rise in net photosynthetic rate was more obvious than canopy apparent photosynthetic rate. The midday depression was present around noon time. The midday depression of the net photosynthetic rate slowly disappeared with the decrease of temperature and then increased to the second peak.

In Figure 7, the diurnal dynamics of both rates showed double-peak curve and midday depression. The canopy apparent photosynthetic rate sharply decreased in midday depression.

3.3 Prediction model of canopy apparent photosynthetic rate based on environmental parameters

\subsubsection{Prediction model at the seeding stage}

At the seeding stage, 162 sets of samples were obtained. Among them, 121 sets were selected as the training samples, and 41 sets $(25 \%)$ were selected as the validation samples. The environmental parameters in the greenhouse were used as input neurons, and the canopy apparent photosynthetic rate was taken as the output neuron.

Table 1 shows the evaluation results of the model. The measured average of the canopy apparent photosynthetic rate was $5.578 \mathrm{mg} / \mathrm{dm}^{2} \cdot \mathrm{h}$, and the predicted average of the canopy apparent photosynthetic rate was $5.591 \mathrm{mg} / \mathrm{dm}^{2} \cdot \mathrm{h}$. In the prediction model, the resulting average performance R, ARE, MAE, and RMSE of the training group were $0.9420,0.1966 \%, 0.6023 \mathrm{mg} / \mathrm{dm}^{2} \cdot \mathrm{h}$, and $0.8988 \mathrm{mg} / \mathrm{dm}^{2} \cdot \mathrm{h}$, respectively. Research results indicated that the model has high accuracy.

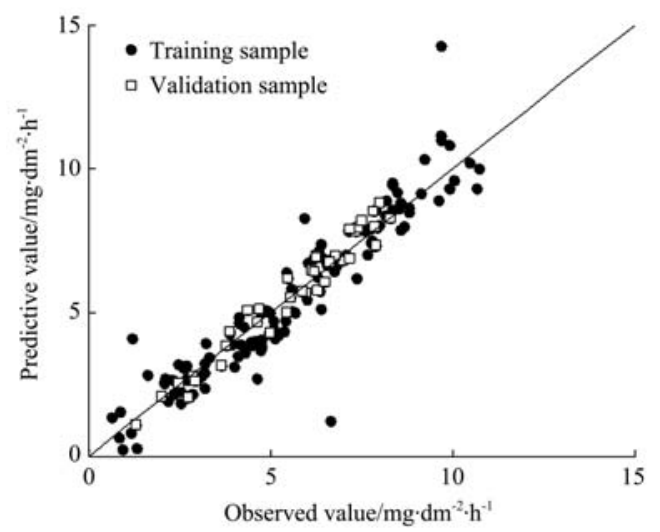

Figure 8 Prediction model of SVM at the seeding stage

\subsubsection{Prediction model at the flowering stage}

At the flowering stage, 152 sets of samples were obtained. Among them, 114 sets were selected as the training samples, and 38 sets $(25 \%)$ were selected as the validation samples. Table 1 shows the evaluation results of the model. The measured average of the canopy apparent photosynthetic rate was 7.234, and the predicted average of the canopy apparent photosynthetic rate was 7.456. In the prediction model, the resulting average performance $\mathrm{R}$, ARE, MAE, and RMSE of the training group were 0.9226, $0.6052 \%, 0.1807 \mathrm{mg} / \mathrm{dm}^{2} \cdot \mathrm{h}$, and $0.8796 \mathrm{mg} / \mathrm{dm}^{2} \cdot \mathrm{h}$, respectively.

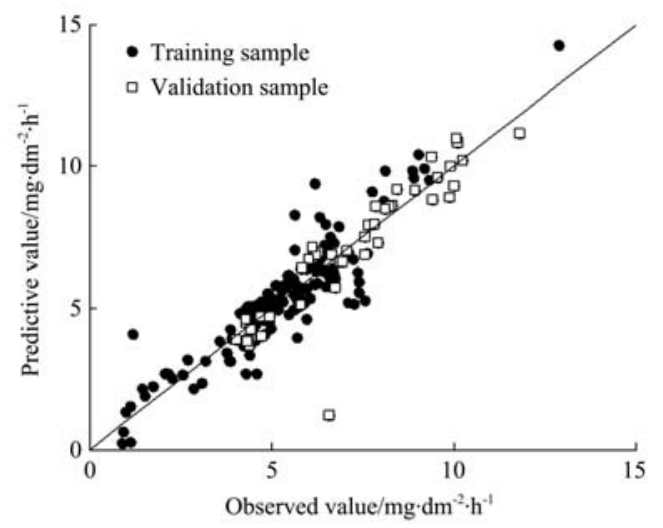

Figure 9 Prediction model of SVM at the flowering stage 
The $\mathrm{R}$ and ARE at the seeding stage were better than those at the flowering stage. However, the RMSE and MAE at the flowering stage were better than those at the seeding stage. As a result, the SVM prediction model has its advantages and disadvantages at different growth stages, and the SVM is an effective method to predict the canopy apparent photosynthetic rate.

Table 1 Accuracy of photosynthesis prediction model at the two growth stages

\begin{tabular}{|c|c|c|c|c|c|c|}
\hline \multirow{2}{*}{ Growth stage } & \multicolumn{2}{|c|}{ Data samples } & \multicolumn{4}{|c|}{ Evaluation indexes } \\
\hline & Measured average $/ \mathrm{mg} \cdot \mathrm{dm}^{-2} \cdot \mathrm{h}^{-1}$ & Predicted average $/ \mathrm{mg} \cdot \mathrm{dm}^{-2} \cdot \mathrm{h}^{-1}$ & $R$ & $\mathrm{ARE} / \%$ & $\mathrm{MAE} / \mathrm{mg} \cdot \mathrm{dm}^{-2} \cdot \mathrm{h}^{-1}$ & $\mathrm{RMSE} / \mathrm{mg} \cdot \mathrm{dm}^{-2} \cdot \mathrm{h}^{-1}$ \\
\hline Seeding stage & 5.578 & 5.591 & 0.9420 & 0.1966 & 0.6023 & 0.8988 \\
\hline Flowering stage & 7.234 & 7.456 & 0.9226 & 0.6052 & 0.1807 & 0.8796 \\
\hline
\end{tabular}

\section{Conclusions}

(1) The measurement system of $\mathrm{CO}_{2}$ assimilation, which was composed of an assimilation chamber, $\mathrm{CO}_{2}$ sensor nodes, and a set of LI-6400XT, was designed to measure the canopy apparent photosynthetic rate. Meanwhile, the control system of $\mathrm{CO}_{2}$ concentration comprised a control instrument, a solenoid valve, a $\mathrm{CO}_{2}$ sensor, and a mixing fan. The system tests showed that the designed system can rapidly and stably measure the canopy apparent photosynthetic rate.

(2) The experimental data in the summer of 2018 were obtained by the canopy apparent photosynthetic rate measurement system and $\mathrm{CO}_{2}$ control system. The differences of diurnal dynamics were analyzed to compare the canopy apparent and net photosynthetic rates. The midday depression of the canopy apparent photosynthetic rate declined sharply.

(3) The prediction model based on the environmental parameters was developed to solve the measurement problem of canopy apparent photosynthetic rate, such as long measuring cycle and high subjective error. The results indicated that the correlation coefficient of the photosynthesis prediction model at the seeding and the flowering stages were 0.9420 and 0.9226, respectively. The experimental results showed that the prediction model has high accuracy after optimizing the parameter $g$ and the penalty factor $\mathrm{c}$. In the next step, we will continue to validate the model at other growth stages of tomatoes.

\section{Acknowledgements}

This work was supported by the Yunnan Academician Expert Workstation (Li Minzan, Grant No. 20170907).

\section{[References]}

[1] Zhou Z J, Su P X, Shi R, Xie T T. Light use efficiency of plants and the environmental impact factors in different alpine ecosystems. Chinese Journal of Ecology, 2017; 6: 1570-1577. (in Chinese)

[2] Kimball B A, Kobayashi K, Bindi M. Responses of agricultural crops to free-air $\mathrm{CO}_{2}$ enrichment. Advances in Agronomy, 2002; 77: 293-368.

[3] Niu Q L, Huang D F. Method for Crop Gross Photosynthesis Measurement in Phytotron. Plant Physiology Communications, 2006; 42(4): 700-704. (in Chinese)

[4] Wu H W, Hai, Tian Y T, Wang Q Y. Prediction Model on Net Photosynthetic Rate of Soybean Plant Groups Based on Kernel Function and Visible Light Spectrum. Spectroscopy \& Spectral Analysis, 2016; 36(6): 1831-1836. (in Chinese)

[5] Long S P, Farage P K, Garcia R L. Measurement of leaf and canopy photosynthetic $\mathrm{CO}_{2}$ exchange in the field. Journal of Experimental Botany, 1996; 47(304): 1629-1642.

[6] Kong X, Xu L, Zhan J H, Peng T, Zhang J, Wang D Z, Huang S, Zhao Q Z.
Screening of high canopy photosynthetic rate rice varieties and its leaf angle characteristics. Journal of Henan Agricultural University, 2018; 52(4): $526-532$.

[7] Shamshiri R R, Jones J W, Thorp K R, Ahmad D, Man H C, Taheri S. Review of optimum temperature, humidity, and vapour pressure deficit for microclimate evaluation and control in greenhouse cultivation of tomato: a review. International agrophysics, 2018; 32(2): 287-302.

[8] Bahare S, Razieh S R, Farukh S, Jacek N, Javad S R. Beneficial effects and potential risks of tomato consumption for human health: An overview. Nutrition, 2019; 62: 201-208.

[9] Li T, Zhang M, Ji Y H, Sha S, Jiang Y Q, Li M Z. Management of $\mathrm{CO}_{2}$ in a tomato greenhouse using WSN and BPNN techniques. Int J Agric \& Biol Eng, 2015; 8(4): 43-51.

[10] Ji Y H, Jiang Y Q, Li T, Zhang M, Sha S, Li M Z. An improved method for prediction of tomato photosynthetic rate based on WSN in greenhouse. Int J Agric \& Biol Eng, 2016; 9(1): 146-152.

[11] Veronica B, Serena M, Susan B, Leeba J, Costantino S, Donatella S. Modelling the biogenic $\mathrm{CO}_{2}$ exchange in urban and non-urban ecosystems through the assessment of light-response curve parameters. Agricultural and Forest Meteorology, 2017; 236(15): 113-122.

[12] Yang P Q, Liu Z G, Ni Z Y, Wang Q S. Remote Sensing of Chlorophyll Fluorescence at Airborne Level Based on Unmanned Airship Platform and Hyperspectral Senso. Spectroscopy and Spectral Analysis, 2013; 11: 3101-3105. (in Chinese)

[13] Qu Y, Xie J F, Wang K, Qi R, Bai X, Zhang K M. Induction and regulation mechanism of low temperature and light on anthocyanin biosynthesis in leaves of Begonia semperflorens. Journal of Henan Agricultural University, 2018; 52(3): 342-349. (in Chinese)

[14] Ye Z P, Yang X L, Kang H J. Comparison of light-use and water-use efficiency for $\mathrm{C} 3$ and $\mathrm{C} 4$ species. Acta Agriculturae Zhejiangensis, 2016; 28(11): 1867-1873. (in Chinese)

[15] Wu X L, Zhang L J, Nie Z X, Yang F, She Y H, Yang W Y. Effects of low light on growth and photosynthetic fluorescence characteristics in soybean seedling. Soybean Science, 2014; 22(1): 53-57. (in Chinese)

[16] Lu Z F, Ren T, Lu J W, Li X K, Cong R H, Pan Y H, et al. Main factors and mechanism leading to the decrease of photosynthetic efficiency of oilseed rape exposure to potassium deficiency. Plant Nutrition and Fertilizer Science, 2016; 22(1): 122-131.

[17] Shamshiri, R. Measuring optimality degrees of microclimate parameters in protected cultivation of tomato under tropical climate condition. Measurement, 2017; 106: 236-244.

[18] Chen Y L, Sun Y G, Kang J, Qi Y, Zhang A M, Chai C Q. Phenetic correlation analasis on the spatial pattern and leaf area index at different scales. Ecological Science, 2017; 36(6): 98-106.

[19] Wang X L, Xu S H, Li Y X. An Installation and Method for Measuring Photosynthetic Rate of Plant Population. Transactions of the CSAE, 1993; 9(4): 62-66. (in Chinese)

[20] Zheng Y, Zhang J P. Application on Error Theory in Data processing of Young's Modulus Experiment. Physics Bulletin, 2018; 37(4): 66-70.

[21] Yin J, Liu X Y, Zhang M, Li H. Photosynthetic rate prediction of tomato plant population based on PSO and GA. 2018; IFAC Paper Online, 2018; pp.61-66.

[22] Li T, Zhang M, Ji Y H, Li M Z. Determing optimal $\mathrm{CO}_{2}$ concentration of greenhouse tomato based on PSO-SVM. Applied Engineering in Agriculture, 2017; 33(2): 157-166. 